\title{
LA FORMATION
}

\section{DE \\ LA PROVINCE ROMAINE D'ASIE \\ PAR}

M. P. FOUCART

MEMBRE DE L'INSTITUT

EXTRAIT

DES MÉMOIRES DE LACADÉMIE DES INSCRIPTIONS ET BELLES-LETTRES

TOME XXXVII

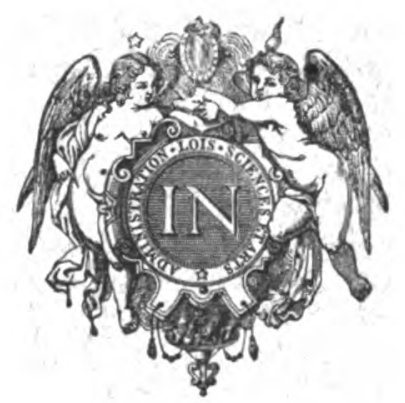

PARIS

IMPRIMERIE NATIONALE

LIBRAIRIE G. KLINGKSIECK, RUE DE LILLE, 11

MDCGGGIII 